\title{
Effect of Manufacturing Errors on the Operation of the Eccentric Rolling Transmission
}

\author{
Stanisław Pabiszczak ${ }^{1 *}$, Wojciech Ptaszyński ${ }^{1}$ \\ 1 Institute of Mechanical Technology, Poznan University of Technology, ul. Piotrowo 3, 60-965 Poznan, Poland \\ * Corresponding author's e-mail: stanislaw.pabiszczak@put.poznan.pl
}

\begin{abstract}
The eccentric rolling transmission consists of rolling bearings mounted eccentrically on the input shaft, cooperating with cam wheels, which are mounted on the output shaft. The aim of this paper was to determine the sensitivity of the transmission to the manufacturing errors of the cam wheel. Two methods of cam wheels milling using a universal CNC machining center were proposed. The measurements of manufactured wheels were performed using a blue light 3D scanner, which allowed the determination of geometric dimensions and deviations from nominal geometry. The experimental research of the eccentric rolling transmission prototype equipped with manufactured cam wheels was conducted, measuring the torque on the gear shafts as a function of its angular position. On the basis of the obtained results, the impact of manufacturing errors on the operation of the transmission unit was examined, especially in terms of torque and efficiency. It was indicated that the machining using ball nose end mill ensures sufficient accuracy of the cam wheels.
\end{abstract}

Keywords: eccentric rolling transmission, cam wheel machining, 3-axis gear milling, gear accuracy, gear geometrical errors.

\section{INTRODUCTION}

Mechanical transmissions are devices particularly sensitive to the manufacturing errors. Ensuring their proper operation, requires the production of parts with small dimensional and shape tolerances, which is often a technological challenge. The search for the roots of transmission errors was the subject of numerous studies, such as [20,23], in which the analytical and statistical methods for evaluating gear units quality were extremely useful.

$\mathrm{Li}[10]$ indicated that the manufacturing errors of gear wheels make the greatest disturbance to the proper operation of the transmission unit and particularly adversely affect the load of the teeth. In addition, the machining inaccuracies - as opposed to the errors arising from the assembly of transmission components - change not only the values but also the course of a torque transmission error. The shape and positional deviations of the transmission components suggested by the author, which do not significantly affect its operation, are less than $0.01 \mathrm{~mm}$. Armilotta [1] presented an analytical method for assessing the assembly errors of a spur gear on the basis of the manufacturing tolerances of its components. In his work, the author assumes that the external forces correspond to the errors at the unit level, while the calculated internal forces and support reactions determine the sensitivity of the part tolerance to a total transmission error. This research indicated that the inaccuracies of holes for shaft bearings in the gear housing had the greatest impact on the torque transmission errors. According to the author, the inaccuracies of the gear wheels had about $50 \%$ lower impact to the transmission error than the manufacturing errors of a gear housing. On the other hand, in [8] it was shown that the eccentricity of gear wheels resulting from their manufacturing had the greatest impact on the transmission errors, followed by the misalignment of holes for shaft bearings in the gear housing and the misalignment of wheels resulting from their assembly. Similar studies were conducted, among others, for cycloid gears. Lin et al. 
[12] indicated that the location of the rollers in the gear housing and the cycloidal wheels profile had the greatest influence on the kinematic accuracy of transmission unit. The examples above emphasize the complex nature of the problem discussed in the paper and the very high sensitivity of the transmissions to gear manufacturing errors.

Over the years, many precise methods of gears machining have been developed, as described in the literature [19]. The existing papers particularly concern the machining of commonly used gears, such as spur, helical or bevel gears. With the development of technology; however, new transmission concepts are emerging for which the use of well-known specialized manufacturing methods is either impossible or unprofitable. This problem is particularly evident when machining prototype gears. The only right solution then seems to be the use of universal CNC machines and the pursuit to obtain the required dimensional and shape accuracy of the product, e.g. when machining gear wheels using the power skiving method [22].

Bouquet et al. [2] compared various gear manufacturing methods, particularly useful for prototype production: Electrical Discharge Machining (EDM), CNC milling and Selective Laser Melting (SLM). As a result of the measurements performed using the coordinate measuring machine (CMM), it was found that the best results due to accuracy and machining time were obtained for $\mathrm{CNC}$ milling. The authors emphasize that greater accuracy of the gear profile was obtained for the EDM method than for milling, but the obtained surface quality was not satisfactory. Malek et al. [14], who analyzed the technology of 5-axis milling of cylindrical gears, added that in order to obtain the proper manufacturing, accuracy it was necessary to develop a machining strategy that includes active tool wear correction.

Undoubtedly, the machine tool itself has a great impact on the quality of the machining. Due to the complex kinematic structure, it is not easy to clearly determine the causes of machine tool errors. Therefore, it seems very useful to predict machining errors, as exemplified by the sensitivity analysis carried out by Li et al. [11]. The authors conducted research to clarify the relationship between errors of tool trajectory and errors of feed drives in a 5-axis CNC milling machine, as a result of which they determined a sensitivity coefficient that allows satisfactory predictions of the machining errors during square-end milling.
In the case of prototype gears, the $\mathrm{CAD} /$ CAM systems are particularly useful, enabling to generate tool paths quickly and accurately, based on a 3D CAD model of the object. In addition, the use of such systems generates new opportunities in the field of design and precision part production, an example of which is the method proposed by Sortino et al. [21]. It involves the manufacturing of a part using a CAM system, and then its optical measurement. The measurement results, in the form of a 3D point cloud, are used to compensate the dimensions and shapes of the base CAD model so that after regenerating machining paths in the CAM environment, it is possible to obtain the product with the required accuracy [7]. Another important aspect associated with CAM systems is the accuracy and the time of machining path generation. Chen and Shi [4] presented a method applicable in 3-axis machining with a ball-end cutter based on the triangulation of free surfaces and then the offset of the triangles vertices of the resulting mesh in a direction normal to the free surface. The projected vertices determine the plane used for mapping the tool path.

In the literature, there are many studies on the manufacturing of gears with a special profile, e.g. cycloidal (epicycloidal) wheels. In the industrial practice, e.g. envelope methods [3] or plastic forming [5] are successfully used, which ensure sufficient accuracy of shape mapping and good surface quality. Lai [9] described the method of generating machining paths and presented a manufacturing of gear wheels with an epicycloid profile using WEDM (Wire Electrical Discharge Machining). In their research, Zhang and Wang [22] dealt with machining of cycloidal wheels on a CNC machine tool using the CAM systems. Dascalescu and Ungureanu [6] described the use of CAD/CAM systems in the design, manufacture (by 3-axis milling) and control of planetary wheels for cycloid gears. Ozel and Ortac [15] presented the original approach to machining of epicycloid wheels by using an end-mill. They developed their own CAM program in $\mathrm{C}++$ environment based on the geometrical analysis of the gear. In addition, they conducted an influence analysis of the geometrical parameters of wheels on the manufacturing errors, as a result of which it was found that as the number of teeth of the wheel increases, the dimensional and shape accuracy decreases. In other studies, Luo et al. [13] dealt 
with the algorithm of avoiding intersection of the tool envelope with the machined profile during 5 -axis finishing milling of cycloidal wheels using an end-mill.

The authors of this article met the problem of the precise manufacturing of prototype gears with a special tooth profile, among others, when working on the project of the eccentric rolling transmission [16]. The studies conducted so far have analyzed the influence of the manufacturing accuracy of selected components of the new transmission on the contact stress values at the contact area of the interacting surfaces [18]. It was proven that the deviation from the nominal eccentricity by $0.05 \mathrm{~mm}$ almost doubled the value of stress at the contact area of cooperating components.

The aim of this paper was to experimentally compare the operation of gear prototypes equipped with cam wheels made by two milling methods using a universal CNC machining center. The authors of the work wanted to determine which of the proposed machining methods provides such dimensional and shape accuracy at which the manufacturing errors do not have a significant impact on the proper operation of the eccentric rolling transmission.

The structure of the article is as follows. Section 2 presents the construction and principle of operation of the eccentric rolling transmission. Section 3 describes the milling methods used for cam wheels, section 4 presents the results of the measurements of cam wheels performed according to various technologies, while section 5 discusses the results of experimental tests.

\section{DESIGN AND PRINCIPLE OF OPERATION OF THE ECCENTRIC ROLLING TRANSMISSION}

The design of the eccentric rolling transmission is shown in Figure 1 and described in detail in [17]. The main elements of the transmission are rolling bearings mounted eccentrically on the input shaft, cooperating with cam wheels with a special profile, which are mounted on the output shaft. Applying the drive to the input shaft causes the outer surfaces of the rolling bearings to roll over the active surfaces of the cam wheels, resulting in the rotation of the output shaft. The cam wheel profile is the envelope of the motion of eccentric rolling units and cam wheels. It depends on the size of the bearings,

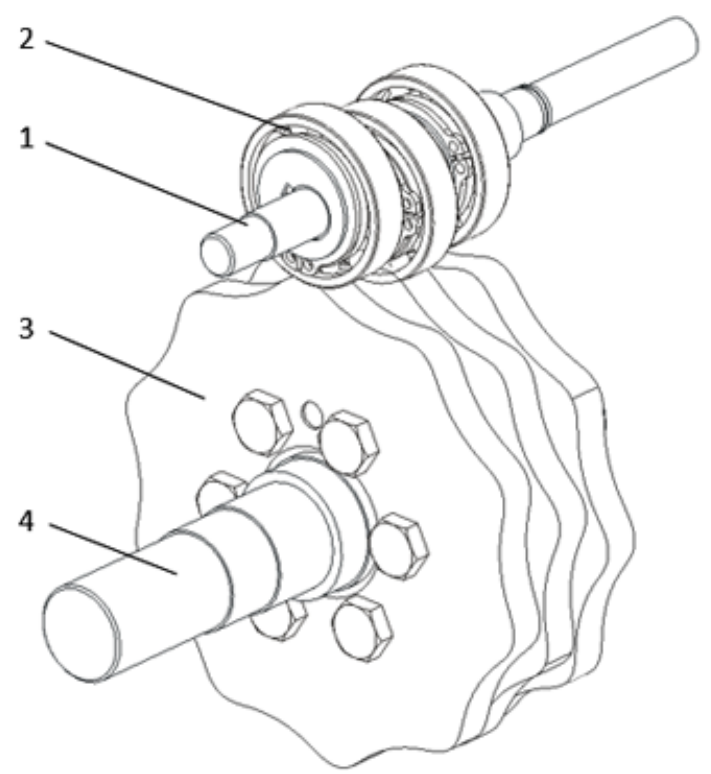

Fig. 1. Design of the eccentric rolling transmission: 1 - input shaft, 2 - eccentric rolling units, 3 - cam wheels, 4 - output shaft

the eccentricity between the input shaft axis and the roller bearing axes, the distance between the shaft axes, as well as the gear ratio. For the proper operation of the transmission, it is necessary to use at least three pairs of eccentric assembly - cam wheel, which ensures the continuity of drive transmission and has a positive effect on the value of the transmitted torque. Due to the rolling elements, the transmission is not selflocking, owing to which it can operate both as a gear reducer and multiplier.

\section{MACHINING METHODS OF CAM WHEELS}

The first prototypes of the eccentric rolling transmission were equipped with three independent cam wheels, evenly distributed relative to the axis of the output shaft, the position of which was determined by six screws mounted into the shaft flange (Fig. 1). This solution enabled simple, quick and accurate machining of the entire cam wheel package on a universal CNC machine tool, but did not ensure the required accuracy of their positioning in the transmission prototype. As a result of experimental research, the use of a compound 3-stage cam wheel was found necessary; however, it caused the need to develop a new machining method. Two methods of machining a 3-stage cam wheel using a T-slot cutter and a ball nose end mill were developed, the details of which are described in this paragraph. 

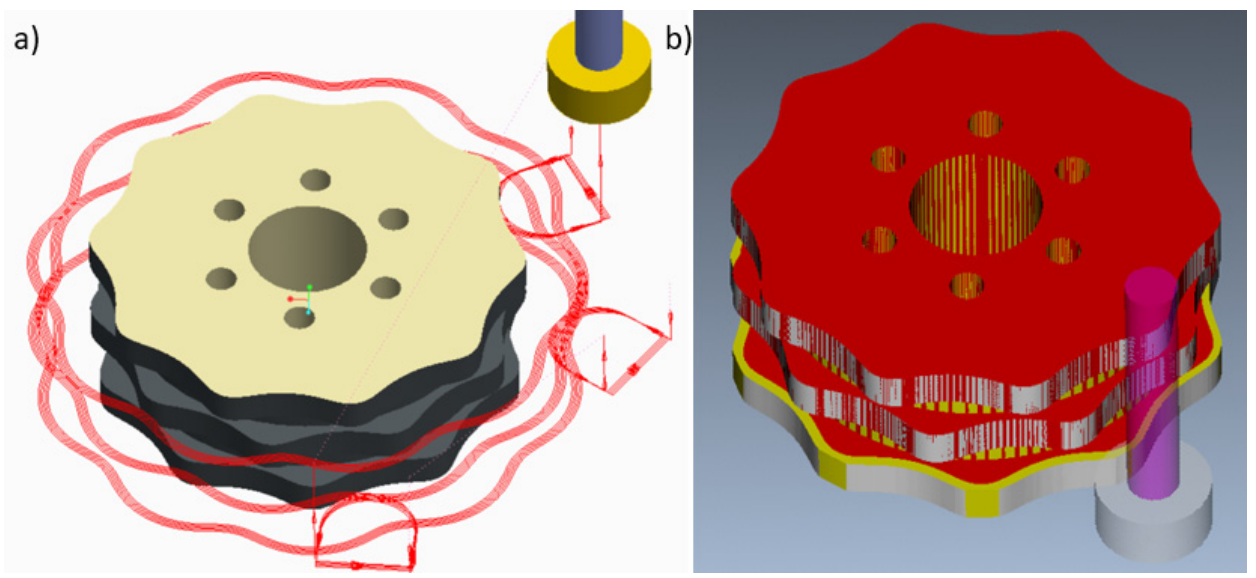

Fig. 2. Development of machining of a 3-stage cam wheel by a T-slot cutter in the CAM program: a) generated tool paths, b) machining simulation

The research work was conducted on a cam wheel made of polyamide PA6 with an $\mathrm{MoS}_{2}$ addition for a transmission unit with a gear ratio equal to 10 .

\section{Machining using T-slot cutter}

The first of the proposed manufacturing methods involved 3-axis machining of a cam wheel by a T-slot cutter with the parameters shown in Table 1. The blank was clamped on a machine tool table using a dedicated machining chuck so that the axis of the blank hole coincided with the $\mathrm{Z}$ axis of the adopted Cartesian coordinate system. All the shaping and adjustment movements in the $\mathrm{X}, \mathrm{Y}$ and $\mathrm{Z}$ axes were carried out by the tool, while the blank remained stationary. The cutter used in this method was characterized by an offset of the cutting

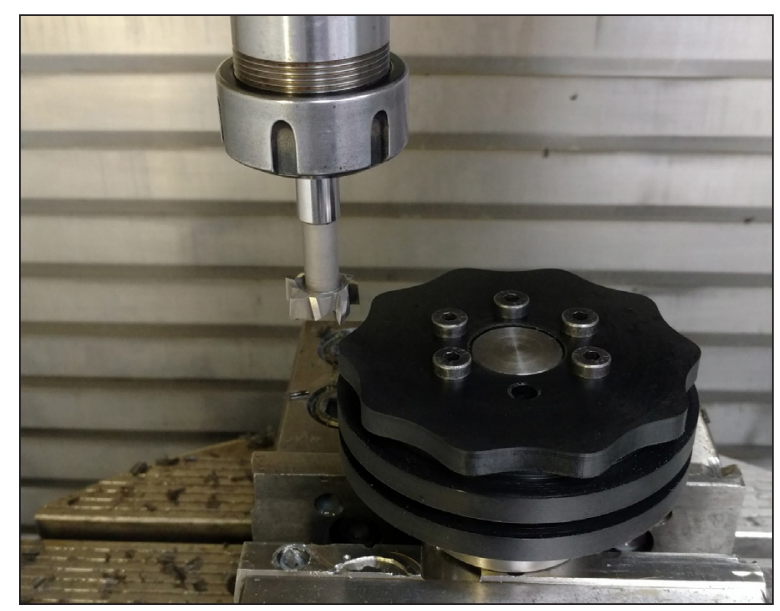

Fig. 3. Roughing a 3-stage cam wheel by a T-slot cutter edge relative to the tool shank, owing to which it was possible to machine each of the three stages of the cam wheel without the risk of collision of the tool shank with the previously machined surfaces. The following machining strategy was adopted: the upper cam wheel stage was roughly milled first (Fig. 3), then the middle one, then the lower one, and then finishing was performed in one pass of the tool for each wheel stage. The tool axis moved along the trajectory corresponding to the offset curve relative to the cam wheel profile, with radial depth cut $a_{e}=0.5 \mathrm{~mm}$, with axial dept cut $a_{p}=7 \mathrm{~mm}$, which corresponded to the width of one stage of the cam wheel.

The roughing of the cam wheel consisted of 5 tool passes for each wheel stage, leaving a finishing allowance of $0.1 \mathrm{~mm}$. A finishing path was generated with an accuracy of $5 \mu \mathrm{m}$. Figure 2 shows the tool paths generated in the CAM program and machining simulation, while Figure 3 shows the result of roughing of the first stage of the cam wheel.

\section{Machining using ball nose end mill}

The second machining method used a ball nose end mill that rotates around the A axis of the machine tool and moves along the $\mathrm{X}, \mathrm{Y}$ and $\mathrm{Z}$ axes, while the workpiece is mounted on a turntable, allowing it to rotate around the $\mathrm{C}$ axis. During roughing, the cutter moved tangentially to the machined profile, with radial depth cut $a_{e}=2 \mathrm{~mm}$ and axial dept cut $a_{p}=2$ $\mathrm{mm}$, leaving a finishing allowance of $0.1 \mathrm{~mm}$. The adopted cutting parameters (Table 1) allowed machining of one cam wheel stage in 
Table 1. Tools and parameters used for cam wheels machining

\begin{tabular}{|l|c|c|}
\hline \multicolumn{1}{|c|}{ Specification } & T-slot cutter DIN851-AA 22x10 & Ball nose end mill HPC 6 \\
\hline Tool material & HSS & VHM + TiAIN \\
\hline Tool diameter $[\mathrm{mm}]$ & 22 & 2 \\
\hline No. of teeth & \multicolumn{1}{|c|}{ Roughing } \\
\hline \multicolumn{2}{|c|}{1555} & 7950 \\
\hline Spindle speed $n[\mathrm{RPM}]$ & 578 & 795 \\
\hline Feed rate $f[\mathrm{~mm} / \mathrm{min}]$ & 7 & 2 \\
\hline Axial depth of cut $a_{\mathrm{p}}[\mathrm{mm}]$ & 0.5 & 2 \\
\hline Radial depth of cut $a_{\mathrm{e}}[\mathrm{mm}]$ & 5 & 5 \\
\hline Number of passes & 34.5 & 35.7 \\
\hline Machining time $T[\mathrm{~min}]$ & Finishing & 7950 \\
\hline \multicolumn{2}{|c|}{1555} & 795 \\
\hline Spindle speed $n[\mathrm{RPM}]$ & 578 & 0.1 \\
\hline Feed rate $f[\mathrm{~mm} / \mathrm{min}]$ & 7 & 0.1 \\
\hline Axial depth of cut $a_{\mathrm{p}}[\mathrm{mm}]$ & 0.1 & 1 \\
\hline Radial depth of cut $a_{\mathrm{e}}[\mathrm{mm}]$ & 1 & 28.5 \\
\hline Number of passes & 6.8 & 64.2 \\
\hline Machining time $T[\mathrm{~min}]$ & 41.3 & \\
\hline Total machining time $[\mathrm{min}]$ & & \\
\hline
\end{tabular}

a)

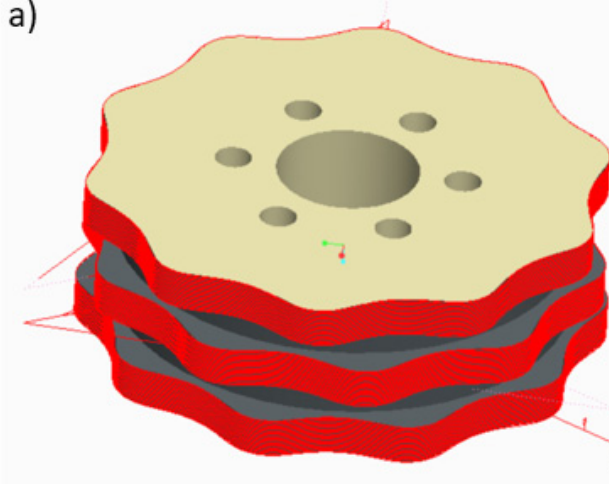

Fig. 4. Development of machining of a 3-stage cam wheel by a ball nose end mill in the CAM program: a) generated tool paths, b) machining simulation

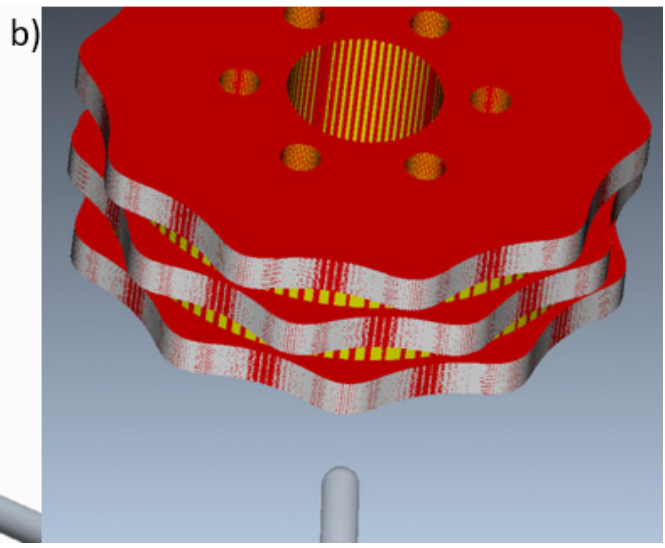

6 passes. A finishing path was also generated with an accuracy of $5 \mu \mathrm{m}$. Figure 4 shows the tool paths generated in the CAM program and machining simulation, while Figure 5 presents the result of machining simulation.

While analyzing the data contained in Table 1 , it can be observed that due to total machining time, the milling using a T-slot cutter turned out to be a more advantageous method, which took about $36 \%$ less time than machining by a ball nose end mill. It is worth noting that the quality of the active surfaces of the cam wheel was comparable in both cases.

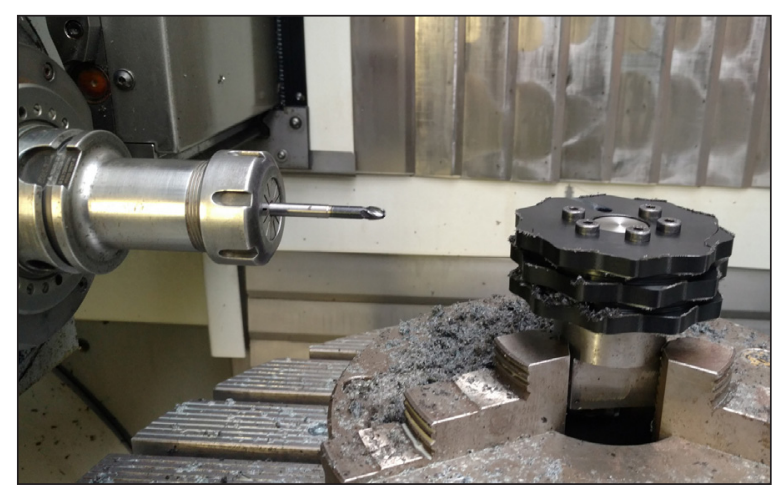

Fig. 5. Roughing a 3-stage cam wheel by a ball nose end mill 


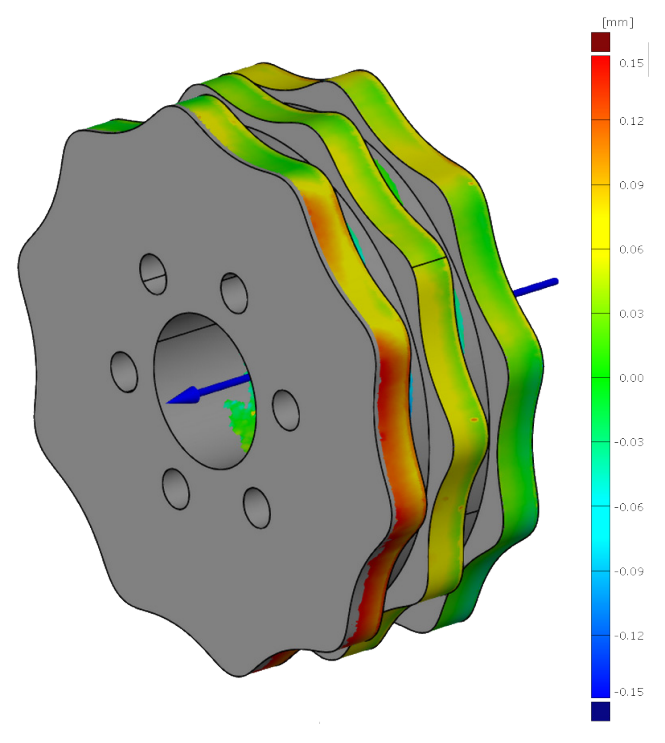

Fig. 6. Distribution of dimensional deviations from the reference model for a cam wheel machined with a T-slot cutter

\section{MEASSUREMENT OF THE CAM WHEELS}

In order to determine which of the adopted machining methods allows obtaining a product with better dimension and shape accuracy, both manufactured cam wheels were measured using the GOM ATOS Compact Scan 5M scanner. The measured cam wheels were covered with a matting spray, and the measuring table was covered with reference points, enabling individual scans to be folded together. A measuring field of 125 $\mathrm{x} 125 \mathrm{~mm}$ was used, owing to which a measurement accuracy of $0.01 \mathrm{~mm}$ was obtained. Using the GOM Inspect software, the results were compared with the reference CAD model of a 3-stage cam wheel using a Best-Fit method. The results of the analysis are shown in Figures 6 and 7.

While analyzing the result of measurement for the cam wheel machined with the T-slot cutter (Fig. 6), it can be observed that the largest deviation from the nominal contour occurs in the first stage of the cam wheel on one side of the contour for about half of its notches. The maximum deviation value is approx. $+0.15 \mathrm{~mm}$, which indicates that the manufactured wheel is larger than the nominal. It is worth noting that for the next stages of the cam wheel, the dimensional deviations have smaller values, especially in the case of the 3rd stage, where their value does not exceed the measurement resolution of the scanner. A similar tendency can be observed for a cam wheel machined with a ball nose end mill (Fig. 7), with the maximum deviations from the nominal profile for the first stage of the cam wheel being clearly smaller (approx. $0.06 \mathrm{~mm}$ ) and having a negative value.

\section{EXPERIMANTAL TESTS}

In order to clearly determine which of the proposed machining methods ensures sufficient dimensional and shape accuracy, the manufactured cam wheels were mounted alternately in the prototype transmission unit and tested. The test setup (Fig. 8) consisted of a servo drive, two torque sensors measuring the torque on the input and output shaft of the transmission, magnetic brake loading the output shaft and an encoder, recording the angular position of the output shaft with high resolution.

The following test program was adopted: the input shaft of the transmission was accelerated to $100 \mathrm{rpm}$, and the output shaft was loaded with 2 and $12 \mathrm{Nm}$, and next the input shaft speed was increased to $1000 \mathrm{rpm}$ and testing for the same loads continued. The torque course graphs for $\mathrm{M}_{1}$ on the input shaft and $\mathrm{M}_{2}$ on the output shaft of the transmission as a function of the output shaft rotation angle $\phi$ were determined for each case, as shown in Figs. 9-12. Due to the cyclical nature of the recorded courses, the graphs show the

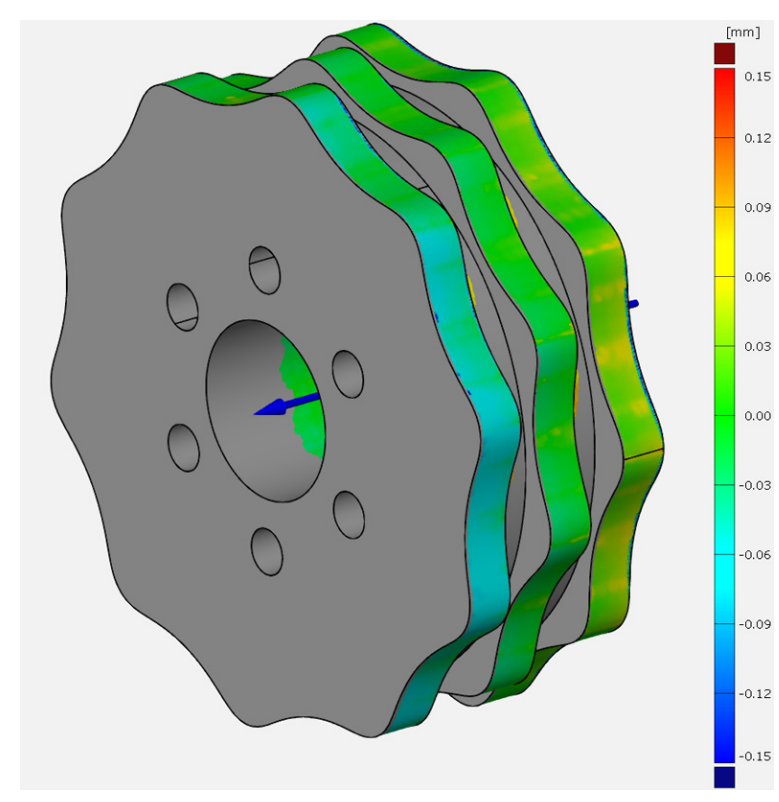

Fig. 7. Distribution of dimensional deviations from the reference model for a cam wheel machined with a ball nose end mill 


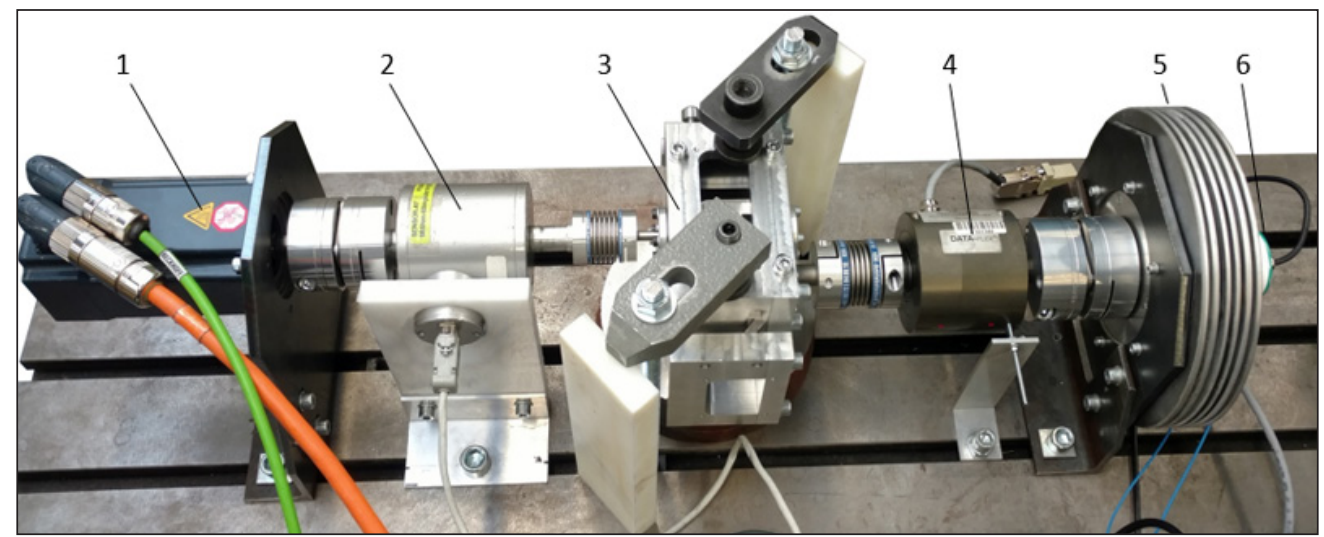

Fig. 8. Test stand: 1 - servo drive, 2 - torque sensor $5 \mathrm{Nm}, 3$ - prototype of the eccentric rolling transmission, 4 - torque sensor $50 \mathrm{Nm}, 5$ - magnetic brake, 6 - encoder

values of torque with respect to one revolution of the output shaft. The results of a detailed analysis of experimental tests are presented in Table 2.

While analyzing the torque course on the input shaft at low rotational speed and low transmission load (Fig. 9), its sinusoidal nature can be observed, resulting from the fact that for each revolution of the output shaft there are 10 rotations of the input shaft. In the discussed case, much better results were obtained for a cam wheel

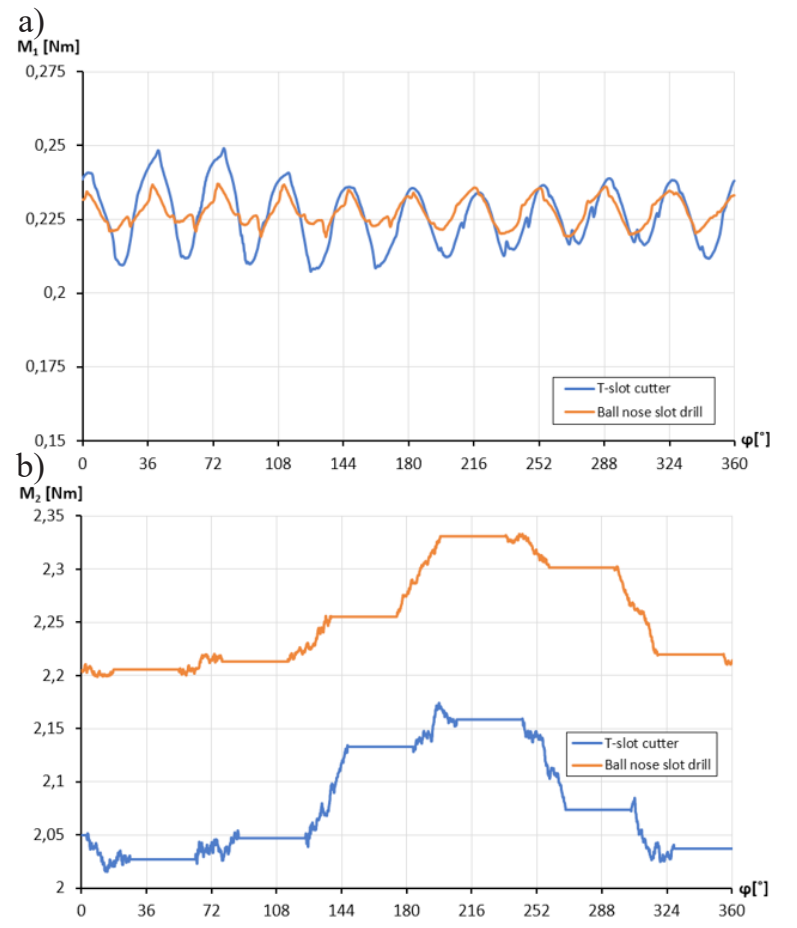

Fig. 9. The results of experimental tests of the transmission prototype for the input shaft rotational speed $\mathrm{n}_{1}=100 \mathrm{rpm}$ and load $\mathrm{M}_{2}=2 \mathrm{Nm}$ : a) $\mathrm{M}_{1}$ torque on the input shaft, b) $M_{2}$ torque on the output shaft machined with a ball nose end mill than for a cam wheel manufactured with a T-slot cutter (values of standard deviation in Table 2). The $\mathrm{M}_{2}$ torque course shown in Figure 9 reflects the dimension and shape inaccuracies of the cam wheel described in the previous paragraph. The results of the measurements indicate that the largest deviation from the nominal cam wheel contour occurs for about half of its notches, which corresponds to the increase in torque $\mathrm{M}_{2}$ for $\phi$ in the range

a)

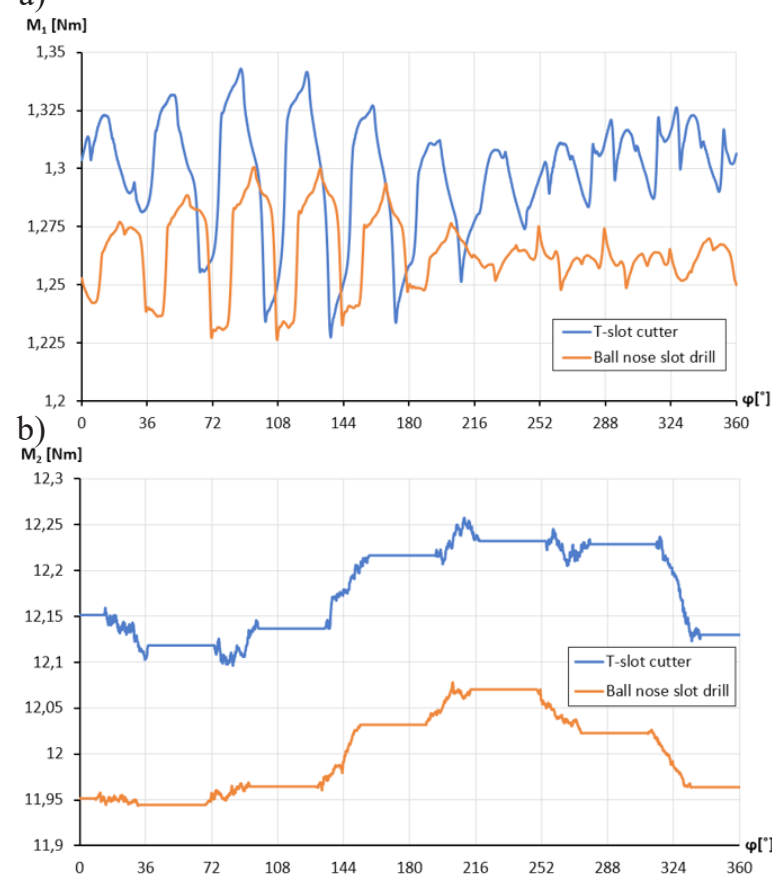

Fig. 10. The results of experimental tests of the transmission prototype for the input shaft rotational speed $\mathrm{n}_{1}=100 \mathrm{rpm}$ and load $\mathrm{M}_{2}=12 \mathrm{Nm}$ : a) $\mathrm{M}_{1}$ torque on the input shaft, b) $M_{2}$ torque on the output shaft 


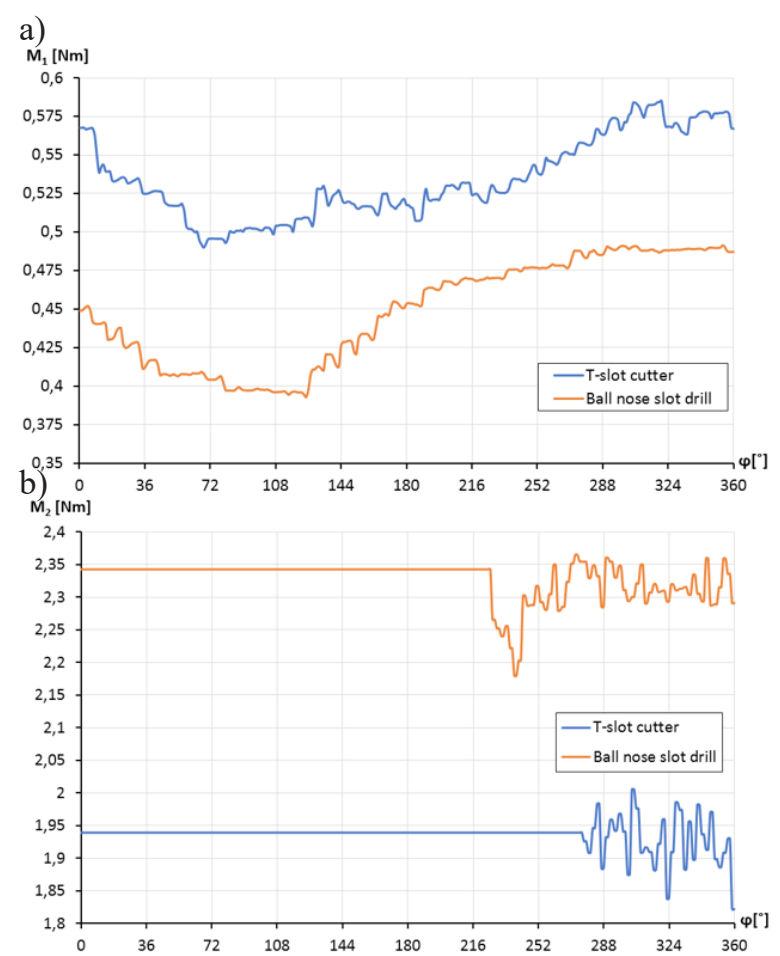

Fig. 11. The results of experimental tests of the transmission prototype for the input shaft rotational speed $\mathrm{n}_{1}=1000 \mathrm{rpm}$ and load $\mathrm{M}_{2}=2 \mathrm{Nm}$ : a) $\mathrm{M} 1$ torque on the input shaft, b) $M_{2}$ torque on the output shaft

120-300 . For the load $\mathrm{M}_{2}=12 \mathrm{Nm}$ (Fig. 10), the differences in the M1 torque course are not as significant as for the smaller load, while the $\mathrm{M}_{2}$ torque course is comparable for the both tested cam wheels, with a similar tendency as in Fig. 9.

The test results for the rotational speed $n_{1}=$ $1000 \mathrm{rpm}$ also confirm that due to the smoothness and stability of drive transmission, better results were obtained for the cam wheels machined by a ball nose end mill. It can be observed that for the load $\mathrm{M}_{2}=2 \mathrm{Nm}$ (Fig. 11), a similar shape of the torque course on the transmission shafts (similar

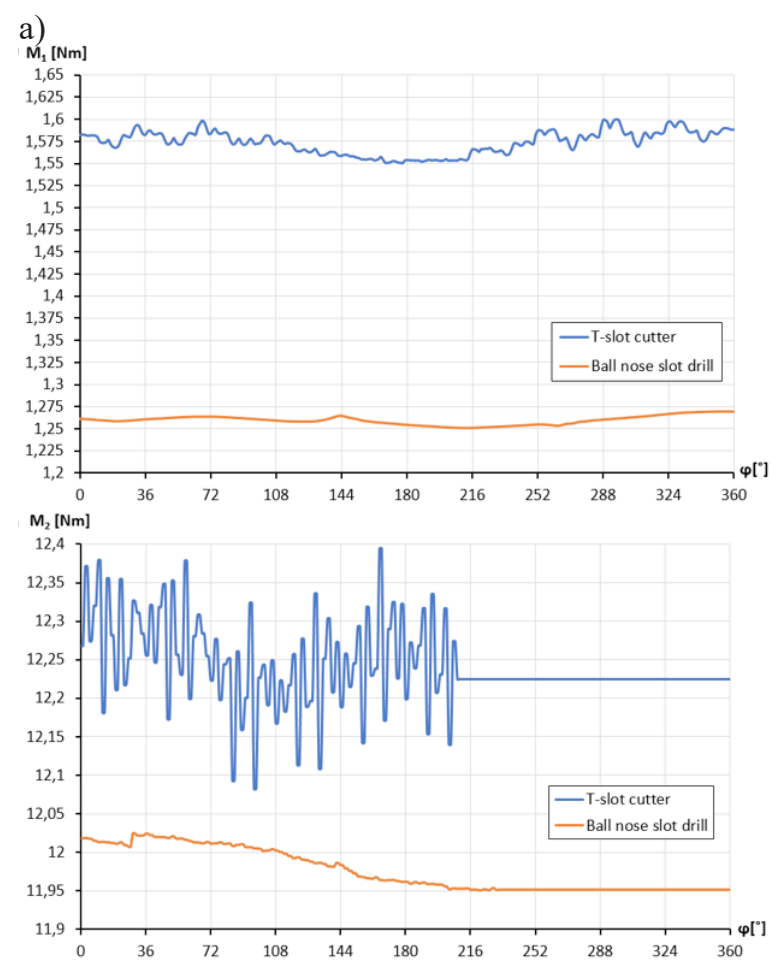

Fig. 12. The results of experimental tests of the transmission prototype for the input shaft rotational speed $\mathrm{n}_{1}=1000 \mathrm{rpm}$ and load $\mathrm{M}_{2}=12 \mathrm{Nm}$ : a) $\mathrm{M}_{1}$ torque on the input shaft, b) $M_{2}$ torque on the output shaft

standard deviation values) was recorded, while with the load $\mathrm{M}_{2}=12 \mathrm{Nm}$ (Fig. 12) the differences between the tested cam wheels are significant. The smallest values of the standard deviation were noted for the wheel machined with a ball nose end mill, which proves the smooth transmission operation and small vibrations.

Better results in terms of the transmission efficiency were also achieved for the cam wheels made with a ball nose end mill (Tab. 2). In each of the studied cases, lower efficiency was obtained for the gears with the cam wheels machined with

Table 2. Analysis of the experimental tests results

\begin{tabular}{|c|c|c|c|c|c|c|c|c|c|}
\hline$n$ [RPM] & $M_{2}[\mathrm{Nm}]$ & Tool & $\begin{array}{l}\Delta M_{1} \\
{[\mathrm{Nm}]}\end{array}$ & $\begin{array}{l}\Delta M_{2} \\
{[\mathrm{Nm}]}\end{array}$ & $\begin{array}{c}\bar{M}_{1} \\
{[\mathrm{Nm}]}\end{array}$ & $\begin{array}{c}\bar{M}_{2} \\
{[\mathrm{Nm}]}\end{array}$ & $s_{M_{1}}$ & $s_{M_{2}}$ & $\begin{array}{c}\eta \\
{[\%]}\end{array}$ \\
\hline \multirow{4}{*}{100} & \multirow{2}{*}{2} & T-slot cutter & 0.042 & 0.159 & 0.226 & 2.079 & 0.010 & 0.050 & 91.91 \\
\hline & & Ball nose end mill & 0.018 & 0.134 & 0.228 & 2.254 & 0.005 & 0.046 & 99.04 \\
\hline & \multirow{2}{*}{12} & T-slot cutter & 0.116 & 0.161 & 1.298 & 12.178 & 0.024 & 0.048 & 93.80 \\
\hline & & Ball nose end mill & 0.074 & 0.134 & 1.264 & 11.999 & 0.016 & 0.044 & 94.92 \\
\hline \multirow{4}{*}{1000} & \multirow{2}{*}{2} & T-slot cutter & 0.095 & 0.183 & 0.534 & 1.936 & 0.026 & 0.021 & 36.25 \\
\hline & & Ball nose end mill & 0.098 & 0.185 & 0.448 & 2.329 & 0.034 & 0.029 & 51.98 \\
\hline & \multirow{2}{*}{12} & T-slot cutter & 0.049 & 0.312 & 1.574 & 12.241 & 0.013 & 0.053 & 77.78 \\
\hline & & Ball nose end mill & 0.019 & 0.074 & 1.260 & 11.976 & 0.005 & 0.027 & 95.08 \\
\hline
\end{tabular}


a T-slot cutter, and the largest differences occurred at the speed $\mathrm{n}_{1}=1000 \mathrm{rpm}$ and load $\mathrm{M}_{2}=$ $12 \mathrm{Nm}$. It should be emphasized that - taking into account the elasto-plastic properties of the material from which the cam wheels are made - the efficiency values for the cam wheels made with a ball nose end mill reaching $95-99 \%$ - should be considered satisfactory.

\section{CONCLUSION}

The test results described in this paper show that the eccentric rolling transmission is particularly sensitive to the cam wheel inaccuracies. As a result of technological analysis, it was found that the cam wheels machined with a T-slot cutter had higher dimensional and shape deviations than the wheels made with a ball nose end mill. In the case of both cam wheels, the maximum dimensional deviations occurred in the first stage of the cam wheels on their one side, which may indicate a misaligned hole in the blank. It is worth noting that the machining of the cam wheels with a T-slot cutter took significantly less time than with a ball nose end mill. It is also important that in the case of the cam wheels with more notches, the difference in the total machining time will gradually increase in favor of milling with a T-slot cutter.

The experimental tests of the transmission prototype equipped with the previously made cam wheels showed that the cam wheel manufactured with a T-slot cutter - in each of the tested rotational speed and load variants - generated greater amplitudes in the course of torque on the input and output shaft. The gear with the wheel made with a ball nose end mill operated with less vibration and much greater efficiency. In addition, there is a correlation between the results of the cam wheel measurements and the results of experimental tests: the torque value on the output shaft of the transmission increases along with the value of the deviation from the nominal cam wheel profile.

The above-mentioned observations allow stating that in the case of eccentric rolling transmission it is necessary to choose the technology enabling manufacturing of the main transmission components with the greatest possible dimensional and shape accuracy. The results of the tests indicate that the machining with a ball nose end mill ensures the accuracy of the cam wheels sufficient for the proper operation of the transmission.
In further research, the authors are planning to focus on investigating the eccentric rolling transmission efficiency, with particular emphasis on the impact of gear ratio and eccentricity value on the obtained results.

\section{Acknowledgements}

The current research is supported by The Ministry of Science and Higher Education (Poland), projects 02/22/DSMK/1487 and 0614/ SBAD/1529.

\section{REFERENCES}

1. Armillotta A. Tolerance analysis of gear trains by static analogy. Mechanism and Machine Theory, 135, 2019, 65-80.

2. Bouquet J., Hensgen L., Klink A., Jacobs T., Klocke F. and Lauwers B. Fast production of gear prototypes - a comparison of technologies, Procedia CIRP, 14, 2014, 77-82.

3. Chang S.L. Studies on epitrochoid gear for cycloid drives. Journal of Mechanics, 19(2), 2003, 271-278.

4. Chen T. and Shi Z. A tool path generation strategy for three-axis ball-end milling of free-form surfaces. Journal of Materials Processing Technology, 208, 2008, 259-263.

5. Chen T.T., Wang J.P., Huang G.M., Hsu M.H., Chen C.L., Hong B.W. and Wey J.M. High-precision technology with negative punch clearance for the manufacturing of a cycloid pump. International Journal of Advanced Manufacturing Technologies, 95, 2018, 1179-1183.

6. Dascalescu A. and Ungureanu M. CAD-CAM programs applied to the cycloid profile wheels processing. Annals of the University of Petrosani, Mechanical Engineerings, 12, 2010, 65-70.

7. Gessner A., Staniek R. and Bartkowiak T. Computer-aided alignment of castings and machining optimization. Proceedings of the Institution of Mechanical Engineers, Part C: Journal of Mechanical Engineering Science, 229(3), 2015, 485-492.

8. Huang X., Hu S., Zhang Y. and Xu Y. A method to determine kinematic accuracy reliability of gear mechanisms with truncated random variables. Mechanism and Machine Theory, 92, 2015, 200-213.

9. Lai T.S. Design and machining of the epicycloid planet gear of cycloid drives. International Journal of Advanced Manufacturing Technologies, 28, 2006, 665-670.

10. Li S. Effects of machining errors, assembly errors and tooth modifications on loading capacity, load-sharing 
ratio and transmission error of a pair of spur gears. Mechanism and Machine Theory, 42, 2007, 698-726.

11. Li Z., Sato R., Shirase K., Ihara Y. and Milutinovic D.S. Sensitivity analysis of relationship between error motions and machined shape errors in fiveaxis machining center - peripheral milling using square end mill as test case. Precision Engineering, 60, 2019, 28-41.

12. Lin K.S., Chan K.Y. and. Lee J.J. Kinematic error analysis and tolerance allocation of cycloidal gear reducers. Mechanism and Machine Theory, 124, 2018, 73-91.

13. Luo S., Liao L., Wang J., Wang Y. and Yi J. Study on inspection and avoidance of interferences in fiveaxis end milling of cycloidal gears. International Journal of Advanced Manufacturing Technologies, 91, 2017, 3307-3314.

14. Malek O., Mielnik K., Martens K., Jacobs T., Bouquet J., Auwers W., Ten Haaf P. and Lauwers B. Lead time reduction by high precision 5-axis milling of a prototype gear. Procedia CIRP, 46, 2016, 440-443.

15. Ozel C. and Ortac Y. A study on the cutting errors of the tooth profiles of the cycloidal gears manufactured in $\mathrm{CNC}$ milling machine. International Journal of Materials and Product Technology, 53(1), 2016, 42-60.

16. Pabiszczak S., Myszkowski A. and Staniek R. Eccentric rolling transmission gear, patent $\mathrm{PL}$ 233658, 2016.

17. Pabiszczak S., Myszkowski A., Staniek R. and Macyszyn $€$. Kinematic analysis and design of eccen- tric rolling transmission, Proceedings of ASME International Mechanical Engineering Congress and Exposition, Tampa, Florida, USA 2017, Vol. 14.

18. Pabiszczak S., Ptaszynski W. and Staniek R. The Impact of Manufacturing Accuracy of Selected Components on Contact Stress in the Eccentric Rolling Transmission. Lecture Notes in Mechanical Engineering, Advances in Manufacturing II, 2, 2019, 176-187.

19. Radzevich S.P. Dudley's handbook of practical gear design and manufacture. CRC Press Taylor \& Francis Group, 2012.

20. Shu Z.H., Shi Z.Y., Chen H.F., Lin J.C. and Kang Y. Research on gear integrated error curves, International Gear Conference, Lyon, France 2014, 418-426.

21. Sortino M., Belfio S., Motyl B. and Totis G. Compensation of geometrical errors of CAM/CNC machined parts by means of 3D workpiece model adaptation. Computer-Aided Design, 48, 2014, 28-38.

22. Tsai C.Y. and Lin P.D. Gear manufacturing using power-skiving method on six-axis CNC turn-mill machining center, International Journal of Advanced Manufacturing Technologies, 95, 2018, 609-623.

23. Wang X.Y., Shi Z.Y., Shu Z.H. and Fu S. Study on evaluation system of gear accuracy based on statistical analysis. International Gear Conference, Lyon, France 2014, 905-913.

24. Zhang C. and Wang Y. Realization on cycloid tooth profile for CNC processing. Applied Mechanics and Materials, 197, 2012, 60-63. 